any observer in the neonatal period to have a click should be treated with prophylactic abduction splintage.

(4) It should be routine practice to observe carefully the hips of any children who present with a congenital foot deformity, whether this be calcaneus or equinus, as often these children have associated hip dysplasia.

(5) We consider that some system of screening during a child's first 12 months of life should be established by public health and infant welfare clinics. We appreciate there may be administrative difficulties, but nevetheless the detection of an unstable hip at six months as compared with 16 months greatly influences treatment and prognosis.

May I stress that, notwithstanding the points raised, von Rosen and Barlow's pioneer work on early screening must receive full acknowledgement. Our concern now is to tighten the net further during the first 12 months of life.-I am, etc.,

\section{ROBERT OWEN}

Robert Jones and Agnes Hunt Orthopaedic Hospital, Oswestry, Salop

SIR.-I must congratulate Mr. Geoffrey Walker on his important and timely article on "Problems in the Early Recognition of Congenital Hip Dislocation" (17 July, p. 147).

Having had personal humbling experience of an eight-month-old child referred to me with frank dislocation of the hip, after finding out that at birth I had examined this child for a mild calcaneo valgus deformity of her foot, I am certain that there are two aethiological types of congenital hip dislocation. My colleague, Mr. Robert Owen, brought this to our notice. 1 In this area we have certainly seen cases present after six months who had been examined by skilled medical personnel at birth and found to have normal hips.

As Mr. Walker states, the memorandum publirhed by the Ministry of Health in 1966 has led most people to believe that full hip examination in the neonate would eliminate any cases of congenital dislocation of hip presenting later. I am glad that $\mathrm{Mr}$. Walker's paper has again brought to our notice that this is not completely so and that all cases with any suspicion of even a mild congenital foot deformity should be followed through until they are walking, to make certain that acetabular dysplasia is not present.-I am, etc.,

\section{P. H. CORKERY}

Prince Edward War Memorial Hospital Rhyl

Owen, R.. Fournal of Bone and foint Surgery,

\section{Tuberous Sclerosis and the Lungs}

SIR.-I would like to point out a misconception in your otherwise interesting and informative leading article on "Tuberous Sclerosis and the Lungs" (10 July, p. 64). Although various mesodermal tumours are seen in patients with this rare disease, it is not true that "Liposarcomata are almost exclusive to tuberous sclerosis." In neither the study of 103 cases of liposarcoma by Enzinger and Winslow in America ${ }^{1}$ nor in our own series of 85 cases from the Westminster Hospital ${ }^{2}$ is the association of liposarcoma and tuberous sclerosis seen. These papers represent the largest series of liposarcomata on both sides of the Atlantic. Liposarcomata are extremely rare in childhood $^{3}$ but the associated mesodermal tumours of tuberous sclerosis commonly present in children.

Liposarcoma is one of the most important of the soft tissue sarcomata both because it is one of the most common and because the chances of cure are often good with a five year survival of $64 \%$. It may occur in association with tuberous sclerosis but it is much more commonly found without it.-I am, etc.,

\section{Meyerstein Institute of Radiotherapy, Middlesex Hospital, \\ 1 Enzinger, F. M., and Winslow, D. J., Virchows Archiv für pathologische Anatomie und Physio- logie und fur klinische Medizin, 1962, 335, 367. 2 Spittle, M. F. Newton K. A., and Mackenzie, D. H., British Fournal of Cancer, 1970, 24, 696. delphia) 1959, 12, 912 .}

Margaret F. SpitTle

SIR,-In your recent leading article on tuberous sclerosis and the lung (10 July, p. 64) you state "Liposarcomata are almost exclusive to tuberous sclerosis."

These are uncommon tumours but neither my colleagues nor I have noticed or heard of any such an association. The most recent authoritative text on soft tissue tumours states "they (liposarcomata) are not related to trauma or any other recognized aetiological factor." Other leading authorities on tumour pathology also fail to mention any association.

Your statement appears to be a quotation from a recent paper by Dwyer et al..$^{2}$ and as they make clear it refers to a paper on liposarcomata of the kidney by Fish and McLaughlin. ${ }^{3}$ Renal liposarcoma is an extraordinarily rare tumour and, in fact, the great majority of liposarcomata arise in other sites. . Tuberous sclerosis may well be associated with the renal liposarcomata ${ }^{3}$ but does not appear to be associated with extrarenal liposarcomata.

I trust you do not think this is too much of a pathologist's quibble. Your leading articles carry considerable authority and it may well be, as a result of the one on tuberous sclerosis, that the relatives of patients with these tumours are subjected to needless investigation of, and much anxiety about, the possibility of a concealed hereditary disease. - I am, etc.,

\section{R. G. M. LETCHER}

Bland-Sutton Institute of Pathology,
Middlesex Hospital Medical School,

London $\mathbb{W} .1$

1 Atlas of Tumour Pathology, Second Series, Fascicle I, 1967, p. 116.

Dwyer, J. M., Hickie, J. B., and Garvan, J., Fish, G. W., and McLaughlin, W. L., fournal
of Urology, 1946, 55, 28 .

\section{Bullous Lesions in Poisoning}

SIR,-We have read Dr. C. M. Ridley's paper on "Bullous Lesions in Nitrazepam Overdosage" (3 July, p. 28) with unusual interest. $\mathrm{He}$ has performed a valuable service in drawing attention to the variety of causes of these lesions in unconscious patients and in concluding "that the bullae represent a reaction to pressure and hypoxia in the skin of the unconscious patient."

We note that his patient had bullae (is it no longer permissible to call them blisters? on "the left side of the face, left hand and wrist, and left breast" (our italics). We found no difficulty in placing a subject in a position in which these parts were subject to considerable pressure (Fig.). From evidence we collected in four cases of $\mathrm{CO}$ or barbiturate poisoning that came under our care ${ }^{1}$ because there had been ischaemic damage of muscle and nerve, as well as of skin we came to the conclusion that the ischaemic lesions occurred only where there was considerable

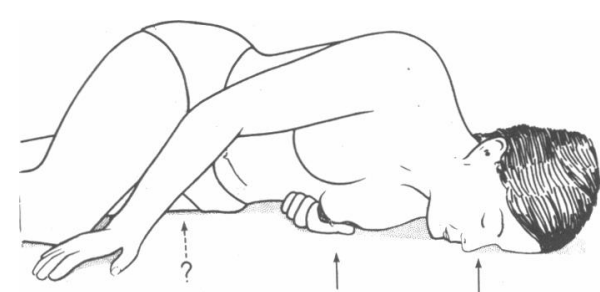

pressure. In this we were about 150 years behind the times; Napoleon's surgeon, Larrey, knew all about it. What puzzles us is that Dr. Ridley does not mention blistering over the left great trochanter; hence our question mark. But he did not, almost certainly because he could not, describe the position in which his patient was found. If it had been what we postulate, it was possible that the upper part of the body was lying on a hard surface and the pelvis on something soft, such as a pillow.

We strongly support his view that it is the combination of pressure and hypoxia that does the damage; the poison that causes unconsciousness is in no way specific.

We are indebted to the Institute of Orthopaedics for placing the facilities of its photographic department at our disposal.

-We are, etc.,

H. J. SEDdON

London W.1

A. J. D. HowsE

1 Howse, A. J. D., and Seddon, H. J., British Medical fournal, 1966, 1, 192.

SIR,-I read with great interest the article by Dr. C. M. Ridley on "Bullous Lesions in Nitrazepam Overdosage" (3 July, p. 28). This raises the question of the origin of these blisters and stimulates me to report a case of barbiturate blistering which I think may shed some light on the aetiology of these lesions.

A 50-year-old man took an overdose of about $25200 \mathrm{mg}$ amylobarbitone capsules and a few amitriptyline tablets on 5 June. He was admitted to hospital deeply unconscious and remained comatose for just over 24 hours after this. On admission to the psychiatric unit here on 8 June blisters surrounded by an erythematous margin were visible over the left acromion process, opposing aspects of the knees, and the inner aspects of the dorsa of the feet and on the lateral aspect of the left foot. By 5 July the blistering and ulceration had healed on the left acromial region and similar lesions on the outer aspect of the left foot were well advanced in healing. However, the ulcers which had been associated with the blistering on the opposing surfaces of knees and 